\title{
Applications of Goods Mutation Control Form in Accounting Information System: A Case Study in Sumber Indah Perkasa Manufacturing, Indonesia
}

\author{
Donny ARIF ${ }^{1}$, Nikma YUCHA ${ }^{2}$, Setiawan SETIAWAN ${ }^{3}$, Dian OKTARINA ${ }^{4}$, \\ Varid MARTAH $^{5}$, Ninnasi MUTTAQIIN ${ }^{6}$
}

Received: June 02, 2020 Revised: June 21, 2020 Accepted: July 12, 2020

\begin{abstract}
This study analyzes the new GMCF method applied by the company with the aim to find out how the production of Accounting Information Systems (AIS) implemented by the company can be managed properly. The study also seeks to find out whether the company needs new system support facilities to facilitate the production performance reporting process of each division and evaluate the performance of GMCF systems in the company. The methods used are descriptive analysis techniques and statistical tests of Paired Sample T-Test comparison; this study uses production data of each unit of a product with random sampling to determine the level of product damage and compare production with the GMCF system and prior to using it. The results of the analysis found that the application of goods mutation control forms (GMCF) greatly influenced the smooth production reporting process, which resulted in an increase in achieving production targets and reducing the risk of product damage during the production process. The company also benefits from the efficiency of production costs when using the GMCF system and can quickly design policies for products that are damaged during the production process. In addition, the company can have damaged products repaired faster than before.
\end{abstract}

Keywords: Accounting Information System, Goods Mutation Control Form, System Production Process, Production Reporting Process, Designing Manufacturing

JEL Classification Code: B21, B26, D24, L15, P11

\section{Introduction}

In the digital era, the business world is developing rapidly in all fields. Competition is no longer about the price

${ }^{1}$ First Author and Corresponding Author. Lecturer, Faculty of Economics and Business, Universitas Maarif Hasyim Latif, Indonesia [Postal Address: Jalan Raya Ngelom Megare, Sidoarjo, Jawa Timur, 61257, Indonesia] Email: doni_arif@dosen.umaha.ac.id

${ }^{2}$ Lecturer, Faculty of Economics and Business, Universitas Maarif Hasyim Latif, Indonesia. Email: nikma@dosen.umaha.ac.id

${ }^{3}$ Lecturer, Faculty of Economics and Business, Universitas Maarif Hasyim Latif, Indonesia. Email: setiawan@dosen.umaha.ac.id

${ }^{4}$ Lecturer, Department of Accounting, STIE Perbanas Surabaya, Indonesia. Email: dian.oktarina@perbanas.ac.id

${ }^{5}$ Lecturer, Faculty of Economics and Business, Universitas Maarif Hasyim Latif, Indonesia. Email: varid_martah@dosen.umaha.ac.id ${ }^{6}$ Lecturer, Faculty of Economics and Business, Universitas Nahdlatul Ulama Surabaya, Indonesia. Email: m.ninnasi@unusa.ac.id

(c) Copyright: The Author(s)

This is an Open Access article distributed under the terms of the Creative Commons Attribution Non-Commercial License (http://Creativecommons.org/licenses/by-nc/4.0/) which permits unrestricted noncommercial use, distribution, and reproduction in any medium, provided the original work is properly cited. level of a product or service or the level of productivity of a company, but rather an emphasis on quality products or services. This new model of goods consumption highlights specific characteristics of product quality related to the location and proximity to the producer (Rossi Scalco et al., 2020). Furthermore, the late 21st century has witnessed revolutionary growth in the information technology management and information system infrastructure networks. In addition, extensive pressure has been applied by the 4th Industrial Revolution on the manufacturing supply chain to stay updated with the IT and IS trends for maintaining Competitiveness (Muneer, 2020). The importance of reducing the difficulty of improving product quality by enhancing the platforms' profitability and consumer surplus is underlined (Wen \& Siqin, 2020). Product quality, convenience, satisfaction, and timeliness in achieving it are the most important factors of success in today's business competition. Understanding perceived market competition among businesses may help explain why certain businesses survive or fail (Byun et al., 2020). The production system is a process of change by utilizing technology by adding 
value to raw materials that are converted into finished goods effectively and efficiently. Many companies, e.g., Sony and Panasonic, have already successfully implemented the GMCF system to gain the flexibility and efficiency advantages that are enabled by the reconfigurable and the multi-skilled workers (Faruk \& Faruk, 2020). In the process of making technological progress and product innovation, both governments and private sectors play important roles in actively searching new innovation tools with high efficiency (Lee \& Xuan, 2019).

Sumber Indah Perkasa is a manufacturing company that carries out automotive maintenance business, and supplies various automotive accessories such as car wash products, body and motorcycle care and polishes. The role of accounting information systems is very large for the company, the production reporting system is implemented effectively and efficiently to avoid fatal mistakes and report manipulation. The company makes a policy of immediately implementing damage control efficiency by creating GMCF so that each division can work through interconnected information technology facilities, therefore good cooperation between divisions is needed. If the board is ineffective in maintaining its role properly, the whole system of governance can collapse (Rahman \& Saima, 2018). This researcher wants to find out whether the entity requires an Accounting Information Systems (AIS) in the production reporting process, and evaluates the effectiveness and application of the Goods Mutation Control Form (GMCF). The Accounting Information Systems (AIS) field, just like the Information Systems (IS) field, covers a broad range of topics. The nature of accounting practices has evolved greatly over the years, especially as information systems have evolved (Kocsis, 2019). There are three factors affecting the accounting information system: a business strategy, information technology development, and organizational culture (Ha, 2020).

This researcher considers that the need for an accurate and maximum accounting information system in the production system reporting process is really needed by manufacturing companies, in order to achieve effective and efficient production, to reduce the cost of the risk of errors in the product manufacturing process, so that the achievement of production targets can be maximized. AIS has evolved over the years to support the growth in the volume of transactions handled, the velocity of transactions supported, the amount of data processed, the variety of data types collected, and sources of data including sensors and external entities. Such complex accounting systems require significant investments and it is critical to minimize errors in AIS (Kim et al., 2017). The conceptual framework of this study explains the evaluation of the application of GMCF in Accounting Information Systems (AIS), the researchers will evaluate before and after the GMCF application of the problem of defective or damaged products and the level of achievement of production targets that affect the reporting process of manufacturing companies' production systems. The application of GMCF in Accounting Information Systems (AIS) affects the smooth reporting of manufacturing company production systems so as to reduce production costs and increase the achievement of production targets (see Figure 1).

\section{Research Methods}

This study uses a quantitative approach, using different test to analyze before and after using GMCF. Quantitative research methods can be interpreted as research methods that use numerical or numerical data, used to examine populations or specific samples, sampling techniques carried out by field surveys, data collection using research instruments, and quantitative data analysis. A quantitative approach is very important to explore the level and variation of changes (within and between units) caused by the implementation strategy (Smith \& Hasan, 2020). Data processing and

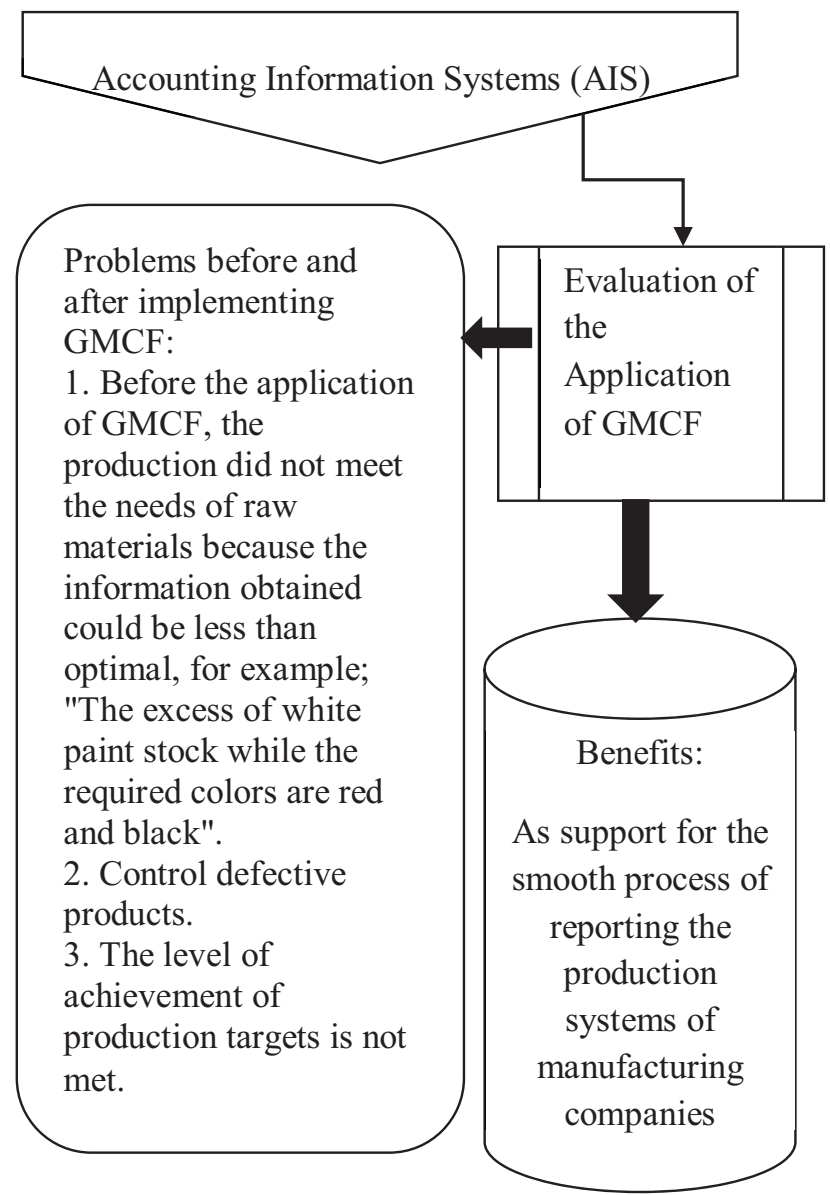

Figure 1: Conceptual Framework 
analysis techniques in this study were performed using Paired Sample T-Test statistical tests. When we are comparing two means and the data have the same people providing measurements of both alternatives (the satisfaction rating of two designs, or the time for the performance of some task for two designs), we have what is referred to as "paired data." The term makes sense, in that a data point from one alternative is identifiably "paired" with a data point from the other alternative (Fritz \& Berger, 2015). The hypotheses are the same as in the previous chapter:

$\mathrm{H} 0: \mu 1=\mu 2$

$\mathrm{H} 1: \mu 1 \neq \mu 2$

Another way to notate the "pairing" of the data is by changing the above notation to

$$
\begin{aligned}
& \text { H0: } \mu 1-\mu 2=0 \\
& \text { H1: } \mu 1-\mu 2 \neq 0,
\end{aligned}
$$

and specify $\mathrm{D}=\mu 1-\mu 2$, where $\mathrm{D}$ means "true average difference" (for the same variable using two alternatives) and write

\section{H0: $\mathrm{D}=0$}

$\mathrm{H} 1: \mathrm{D} \neq 0$

In other words, is the average (true) difference (D) between the time it takes for someone to do two zero tasks (H0 true) or not zero (H0 false, $\mathrm{H} 1$ true). If we accept $\mathrm{H} 0$ (concluding that $\mathrm{HO}$ is true), this actually says that there is not enough evidence to reject H0 (Fritz \& Berger, 2015). Here are the hypotheses:

H0: There is no difference before and after the application of GMCF in the Accounting Information System (AIS) as a supporting reporting system for manufacturing companies.

H1: There are differences before and after the application of GMCF in Accounting Information Systems (AIS) as a support for the smooth reporting of manufacturing companies' production systems.

Paired Test Formula Sample t-test:

$$
t=\frac{x_{1}-x_{2}}{\sqrt{\frac{s_{1}^{2}}{n_{1}}+\frac{2^{2}}{n_{1}}-2 \mathrm{r}\left(\frac{s_{1}}{\sqrt{n_{1}}}\right)\left(\frac{s_{2}}{\sqrt{n_{2}}}\right)}}
$$

Information:

$\mathrm{x} 1=$ Sample Average 1

x2 $=$ Sample Mean 2

s1 $=$ Sample Standard Deviation 1

s2 $=$ Sample Standard Deviation 2 s12 = Sample Variance 1

s22 $=$ Sample Variance 2

$\mathrm{r} \quad=$ Correlation between two samples

Correlation Coefficient:

$\mathrm{r}_{x y}=\frac{x y}{\sqrt{\sum x^{2} y^{2}}}$

Information:

$\mathrm{r}_{\mathrm{xy}}=$ Correlation between variables $\mathrm{x}$ with $\mathrm{y}$

$\mathrm{x}=\left(\mathrm{x}_{\mathrm{i}}-\mathrm{x}\right)$

$\mathrm{y}=\left(\mathrm{y}_{\mathrm{i}}-\mathrm{y}\right)$

Decision:

$\mathrm{H} 0$ is accepted if : $\mathrm{Sig}>0.05$ (not significant)

H1 accepted if $\quad:$ Sig $<0.05 *$ (significant)

: Sig $<0.01 * *$ (very significant)

\section{Results}

Percentage of production target achievement data before and after the application of GMCF that will be tested by researchers (see Table 1).

Table 1: Data Percentage of Production

\begin{tabular}{|l|c|c|}
\hline \multirow{2}{*}{\multicolumn{1}{|c|}{ Division }} & \multicolumn{2}{c|}{$\begin{array}{c}\text { Percentage of Production } \\
\text { Target Achievement (\%) }\end{array}$} \\
\cline { 2 - 3 } & Before & After \\
\hline Injection & 73,2 & 91,2 \\
\hline Burrs & 73,1 & 91 \\
\hline Rub & 73 & 90,9 \\
\hline Wash & 72,8 & 90,8 \\
\hline Spray & 72,1 & 89,8 \\
\hline Sticker \& Logo & 72 & 90,9 \\
\hline Fernish & 71,9 & 90,8 \\
\hline Lis & 71,8 & 90,7 \\
\hline PVC & 71,7 & 90,6 \\
\hline Sterofoam & 71,5 & 90,5 \\
\hline Assembly & 71,2 & 90,4 \\
\hline Garment & 72,9 & 89,9 \\
\hline Average & 72,27 & 90,63 \\
\hline Total & 939,47 & $1.178,13$ \\
\hline Average Difference & & 18,36 \\
\hline Total & & 238,66 \\
\hline
\end{tabular}


From Table 1, the researcher will test the data before and after the application of GMCF, and the percentage of production target data achievement so that differences can be known. The normality test is used in this study to see whether the data to be used are a normal distribution or not (see Table 2). The normality test presents statistics to test complete samples, test distribution assumptions for other locations, and family-scale distributions (Öztürk, 1988). A large proportion of such test procedures are reviewed and listed by Shapiro and Brain (Öztürk, 1988).

The results of the normality test before and after the application of GMCF showed that the data were normally distributed, the significance value of the Shapiro-Wilk test showed more than 0.05 , before the application of 0.211 and after the application of 0.199 . In this section we will concentrate on design with paired samples (see Table 3): the t test for paired samples with a mean, because this is the only test found in our review (Rietveld \& van Hout, 2017) the Wilcoxon Signed Ranks test (WSR.

The results of the descriptive statistics summary of the two sample data on the average achievement of production targets before and after the application of the Goods Mutation Control Form (GMCF) increased. So, basically, the evaluation before or after the completion time is "paired." One person gives two data points and we know which two come from the person given (Fritz \& Berger, 2015). Descriptive statistical test results showed that before the application of GMCF, the average achievement of production targets was 72.2667 percent, whereas after the application of FPMB, the average achievement of production targets was as much as 90.6250 percent. $\mathrm{N}$ indicates the amount of data that is before and after as many as 12 , standard deviations indicate heterogeneity that occurs in data before and after an application is 0.69326 and 0.42239 . Standard Error Mean before and after an application is 0.20013 and 0.12193 .

With the implementation of GMCF in the previous month, the value of Reject decreased dramatically by 39 units with

Table 2: Normality Test (Saphiro-Wilk)

\begin{tabular}{|l|c|c|}
\hline \multicolumn{1}{|c|}{ Indicator } & DF & Sig \\
\hline Before & 12 & 0,211 \\
\hline After & 12 & 0,199 \\
\hline
\end{tabular}

Table 3: Paired Sample Statistic

\begin{tabular}{|l|c|c|c|c|}
\hline Indicator & $\mathbf{N}$ & $\begin{array}{c}\text { Mean } \\
\text { Value }\end{array}$ & $\begin{array}{c}\text { Standard } \\
\text { Deviation }\end{array}$ & $\begin{array}{c}\text { Standard } \\
\text { error Mean }\end{array}$ \\
\hline Before & 12 & 72,2667 & 0,69326 & 0,20013 \\
\hline After & 12 & 90,6290 & 0,42239 & 0,12193 \\
\hline
\end{tabular}

a percentage of $0.85 \%$ from the production of 4,611 units. Whereas in the months before GMCF implementation, the Reject Production figures were very high and the production results were less than the maximum, the total production of 3,623 units with a reject production value of 102 units with an average percentage of 2.81 percent per month. This approach considers the estimation equation approach to estimate the correlation function of the pair, but for Alpha numbers $>0.05$ (Coeurjolly et al., 2019) there is no relationship between before and after using GMCF (see Table 4).

Correlation test results show that the correlation of two variables amounted to 0.310 with a significance of 0.326 . Shows that the correlation between the two average achievements of production targets before and after the application of the Goods Mutation Control Form (GMPF) is no significant (see Table 5).

The basis for the decision to accept or reject $\mathrm{H} 0$ in this test is as follows.

1. If $\mathrm{t}$ - value $>\mathrm{t}$-table and probability (Asymp.Sig) $<0.05$, then $\mathrm{H} 0$ is rejected and $\mathrm{H} 1$ is accepted.

2. If t- value $>$ t-table and probability (Asymp.Sig) $>$ 0.05 , then $\mathrm{H} 0$ is accepted and $\mathrm{H} 1$ is rejected.

The $\mathrm{t}$-value is $-92,061$ with sig 0,000 . Because the sig value $<0.05$, it can be concluded that $\mathrm{H} 1$ is accepted, meaning that the average achievement of production targets before and after the implementation of the Goods Mutation Control Form (GMCF) is that there are differences, thus it can be stated that the application of the Goods Mutation Control Form (GMCF) is very influential on smooth production reporting process so that the achievement of production targets increases.

\section{Discussion}

The research conducted aims to determine the differences before and after the application of the Goods Mutation Control Form (GMCF). Before GMCF, Sumber Indah Perkasa Manufacturing uses the form in the shape of a table

Table 4: Correlations Test

\begin{tabular}{|c|c|c|c|}
\hline Indicator & t-Value & t-table & Sig (2-tailed) \\
\hline Before and After & 92,061 & 1,7823 & 0,000 \\
\hline
\end{tabular}

Table: 5 Paired Sample t-test

\begin{tabular}{|c|c|c|c|}
\hline \multicolumn{4}{|c|}{ Paired Sample Correlations } \\
\hline Indicator & $\mathbf{N}$ & Correlation & Sig \\
\hline Before and After & 12 & 0,310 & 0,326 \\
\hline
\end{tabular}


of production results in each division and filling the table separately by each division, so there is no supervision of an item in the production process. Researchers and all company staff concerned designed a new information system in the form of a GMCF (All Items Mutation Control Form). GMCF is an Accounting Information System (AIS) that is used by Sumber Indah Perkasa Manufacturing as the basis of information that will be used in accounting data management, so that data that has been processed can be recapitalized for information needs such as salary bonuses, a recapitulation of production results, production costs, PPIC and needs other information. The recording system in each GMCF is filled by all divisions in one form that runs according to the production process and according to the order of the divisions so that they are no longer separate as before. The GMCF was designed based on the results of a meeting with researchers, staff teams, and all heads of the company's production divisions so that goals and targets can be achieved together.

GMCF is composed of all divisions such as the injection, grinding, rubbing, washing, paint, sticker, fernish, trim, PVC, styrofoam, and assembly divisions. The code format used in GMCF is an arrangement of numbers, (4.2) is derived from the date and number of the GMCF order issued, and the combination ( $\mathrm{J} / 18)$ where " $\mathrm{J}$ " is the number of months used as letters and " 18 " is the year of GMCF making. Example: On 4 October 2018 there are eight helmet production orders to be issued so that the code format is $[4.1 \mathrm{~J} / 18][4.2 \mathrm{~J} / 18]$ [4.3 J / 18] [4.4 J / 18] [4.5 J / 18] [ $4.6 \mathrm{~J} / 18]$ [4.7 J / 18] [4.8 $\mathrm{J} / 18]$ at each GMCF issued for processing based on the order and the process flow of each production division. Based on the results of research conducted before and after the application of GMCF on Accounting Information Systems (AIS) is a support for the smooth process of reporting the production system of manufacturing companies that can be assessed through rejecting data on production results and the percentage of achievement of production targets.

\section{Conclusion}

It was concluded that, through the application of GMCF, the information obtained becomes accurate and it is known which division is more dominant in defective goods, so that an appropriate handling policy can be made on the number of defective goods, namely, through the policy of making GMCF By-Pass. GMCF By-Pass is made to manage defective goods so that it has the same sale value again while maintaining the quality of the product produced, by reducing the number of defective goods the factory overhead costs can be minimized. Given the results of the summary of the descriptive statistics of the two data sample, the average achievement of production targets before and after the application of the Goods Mutation Control Form (GMCF) rose from 72.2667 to 90.6250 . Increasing the percentage of production targets by using GMCF proves that Accounting Information Systems (AIS) are very helpful in managing the company's needs to deal with increasingly complex problems so that work becomes more effective and efficient. Thus, it can be stated that the application of the Goods Mutation Control Form (GMCF) is very influential on the smooth process of production reporting so that production targets are achieved.

The results of the correlation test shows that the correlation between the two variables concluded there was no significant relationship between before and after. This shows that there is no significant correlation between the two average achievements of production targets before and after the application of the Goods Mutation Control Form (GMCF). Based on the results of hypothesis testing or paired samples t-test, it was concluded that $\mathrm{H} 1$ was accepted, meaning that the average achievement of production targets before and after the application of the Goods Mutation Control Form (GMCF) was different, thus it could be stated that the application of the Goods Mutation Control Form (GMCF) greatly influences the smooth production reporting process so that the achievement of production targets increases.

\section{References}

Byun, S. E., Han, S., Kim, H., \& Centrallo, C. (2020). US small retail businesses' perception of competition: Looking through a lens of fear, confidence, or cooperation. Journal of Retailing and Consumer Services, 52(June 2019), 101925. https://doi. org/10.1016/j.jretconser.2019.101925

Coeurjolly, J. F., Cuevas-Pacheco, F., \& Waagepetersen, R. (2019). Second-order variational equations for spatial point processes with a view to pair correlation function estimation. Spatial Statistics, 30, 103-115. https://doi.org/10.1016/j. spasta.2019.03.001

Faruk, O., \& Faruk, O. (2020). Journal Pre-proof. https://doi. org/10.1016/j.cor.2020.104917

Fritz, M., \& Berger, P. D. (2015). Comparing two designs (or anything else!) using paired sample T-tests. Improving the User Experience Through Practical Data Analytics, 1993, 71-89. https://doi.org/10.1016/b978-0-12-800635-1.00003-3

Ha, V. D. (2020). Impact of organizational culture on the accounting information system and operational performance of small and medium sized enterprises in Ho Chi Minh City. Journal of Asian Finance, Economics and Business, 7(2), 301-308. https:// doi.org/10.13106/jafeb.2020.vol7.no2.301

Kim, R., Gangolly, J., \& Elsas, P. (2017). A framework for analytics and simulation of accounting information systems: A Petri net modeling primer. International Journal of Accounting Information Systems, 27(September), 30-54. https://doi. org/10.1016/j.accinf.2017.09.002 
Kocsis, D. (2019). A conceptual foundation of design and implementation research in accounting information systems. International Journal of Accounting Information Systems, 34, 100420. https://doi.org/10.1016/j.accinf.2019.06.003

Lee, J. W., \& Xuan, Y. (2019). Effects of technology and innovation management and total factor productivity on the economic growth of China. Journal of Asian Finance, Economics and Business, 6(2), 63-73. https://doi.org/10.13106/jafeb.2019. vol6.no2.63

Muneer, S. (2020). The information system management and its infrastructure for supply chain management as antecedents of financial performance. Journal of Asian Finance, Economics and Business, 7(1), 229-238. https://doi.org/10.13106/ jafeb.2020.vol7.no1.229

Öztürk, A. (1988). On a test statistic for testing normality. Computational Statistics and Data Analysis, 6(2), 91-98. https://doi.org/10.1016/0167-9473(88)90039-4

Rahman, M. M., \& Saima, F. N. (2018). Efficiency of board composition on firm performance: Empirical evidence from listed manufacturing firms of Bangladesh. Journal of Asian
Finance, Economics and Business, 5(2), 53-61. https://doi. org/10.13106/jafeb.2018.vol5.no2.53

Rietveld, T., \& van Hout, R. (2017). The paired t test and beyond: Recommendations for testing the central tendencies of two paired samples in research on speech, language and hearing pathology. Journal of Communication Disorders, 69, 44-57. https://doi.org/10.1016/j.jcomdis.2017.07.002

Rossi Scalco, A., Miller Devós Ganga, G., Cristina De Oliveira, S., \& Baker, G. (2020). Development and validation of a scale for identification of quality attributes of agri-food products in short chains. Geoforum, 111(October 2019), 165-175. https:// doi.org/10.1016/j.geoforum.2020.02.012

Smith, J. D., \& Hasan, M. (2020). Quantitative approaches for the evaluation of implementation research studies. Psychiatry Research, 283(March), 112521. https://doi.org/10.1016/j. psychres.2019.112521

Wen, X., \& Siqin, T. (2020). How do product quality uncertainties affect the sharing economy platforms with risk considerations? A mean-variance analysis. International Journal of Production Economics, 224, 107544. https://doi.org/10.1016/j. ijpe.2019.107544 